\title{
Confronting the Insider-Outsider Polemic in Conducting Research with Diasporic Communities: Towards a Community-Based Approach
}

\author{
Bruce A. Collet
}

\begin{abstract}
Researchers focusing on diasporic contexts face the difficult task of wearing their "academic hats" while at the same time building meaningful relationships with immigrant communities. This is no more apparent (and important) than with "non-community" (i.e., outsider) researchers. Here diasporic communities, having already experienced the trauma of forced migration, must see the academic researcher as one they can trust and who is invested in their long-term well being. In this paper I address methodological and philosophical concerns related to the insider-outsider researcher distinction and to conducting research as an "outsider." The principle aims of the paper are to critically examine the distinctions that create and perpetuate the insider-outsider polemic, explore what this polemic "looks like" within diasporic contexts, and consider community-based participatory research as one "vehicle" that might effectively address some of the thorniest problems associated with the insideroutsider distinction.
\end{abstract}

\section{Résumé}

Les chercheurs consacrant leurs travaux aux contextes diasporiques sont confrontés à la difficile tâche de porter leurs "chapeaux d'universitaire" et d'établir en même temps des rapports significatifs avec les communautés d'immigrés. Cela est encore moins évident (et important) pour les chercheurs "non communautaires" (c.-à-d., étrangers). Les communautés diasporiques, ayant déjà éprouvé le traumatisme de la migration forcée, doivent percevoir le chercheur universitaire comme quelqu'un en qui elles peuvent faire confiance et qui tient à cour leur bien-être à long terme. Dans cet article, je traite des problèmes d'ordres méthodologiques et philosophiques liés à la distinction entre chercheur initié et chercheur étranger, et à la conduite des recherches en tant qu'"étranger". Les objectifs principaux de cet article sont d'examiner de façon critique les distinctions qui créent et qui perpétuent la polémique initié-étranger, d'explorer comment cette polémique est perçue dans des contextes diasporiques, et de considérer la recherche participative communautaire comme un " véhicule " qui pourrait traiter de façon efficace certains des problèmes les plus épineux liés à la distinction initié-étranger

I

$\mathrm{n}$ this paper I address the insider-outsider researcher distinction as it relates to conducting research with diasporic communities. ${ }^{1}$ While the distinction has in many cases legitimate historical precedent and real perpetuating factors (such as racism and classism), basic philosophical problems associated with the dualism, such as group boundaries and group membership,remain. The distinction becomes even more complicated in this regard given the fluid and dynamic nature of diasporic communities wherein there may exist multiple homes and multiple belongings. ${ }^{2}$ Yet despite philosophical complications with the insideroutsider dualism, ethical issues pertaining to non-refugee academics engaging in refugee research persist. Most pertinent is the fulfillment of what Karen Jacobsen and Loren 
Landau identify as the "dual imperative" in refugee research, namely, to satisfy rigorous academic research standards while also ensuring that the knowledge and understanding generated by forced migration research be used toward the advancement of refugee protection and the betterment of refugee policy. ${ }^{3}$ Community-based participatory research is one vehicle that might effectively address some of the thorniest problems associated with the insider-outsider distinction related to research with diasporic communities and concomitantly address the imperative articulated by Jacobsen and Landau. This is particularly so with regard to bridging the academic-community divide and herein (re)defining the role of the outsider researcher and his / her relation to diasporic communities at large.

I begin this article with an overview of the basic ways in which the insider-outsider researcher distinction has been created and maintained, giving special attention to the manners in which universities and communities, and academic and non-academic cultures, have been separated. I then move to examining complications regarding the distinction, including the special context of research within diasporic contexts. Thirdly I attend to Jacobsen and Landau's dual imperative in refugee research, drawing relations between the imperative and "outsider" researcher. I conclude the article with a discussion of community-based research, and the promises it holds for both the researcher and the researched.

\section{Conceptualizing and Understanding Insider-Outsider Distinctions}

The term "outsider researcher" with reference to relations between researcher and the researched is most basically understood in terms of group membership, wherein an "outsider" is a non-"member" of the community in question. Hence a man researching women, a black researching whites, and a heterosexual researching gays may all be said to be "outsider" researchers by virtue of their not being women, whites,or gays. By the same token, members of these communities conducting research about these communities may be construed as "insider" researchers. The implicit assumption behind distinguishing insiders from outsiders based on group membership is that only such insiders can properly understand and represent the experience of their community. ${ }^{4}$

Yet basic group membership or non-membership only scratches the surface of the reasons for and tensions inherent in insider-outsider distinctions, and there are far weightier concerns. Chief among these is the existence of unequal power relations between the researcher and the researched, and the very real possibilities of abuse and exploitation. Criminal practices in human experimentation such as those carried out by the Nazis in concentration camps during World War II, the Imperial Japanese Army on war prisoners in the infamous Unit 731 (Second SinoJapanese War and World War II), and by the US government on African-American males (te Tuskegee Syphilis Study, 1932-1972) are some of the most glaring examples of abuse of power carried out by "outside" researchers. ${ }^{5}$ In other cases, while perhaps not overtly criminal, power imbalances between the researcher and the researched can still lie at the heart of very questionable research ethics, particularly where there is a lack of informed consent or full knowledge of the research goals and methodology. ${ }^{6}$

Intrinsic also to power dynamics is what Meredeth Minkler depicts as a "dialectic of resistance" between outsider researchers and communities which have experienced historical trauma and internalized oppression, such as $\mathrm{Na}$ tive and African communities in North America. ${ }^{7}$ Here researchers who are "members" of the subordinating group (most typically white men of European desent) are either rejected or viewed with great suspicion and mistrust based on what they historically represent to the community. Even in cases where such outsider researchers purport to act in an emancipatory way by "giving voice to" the neglected and disenfranchised, communities may still reject such efforts on the basis of not wanting to depend on outsiders for their representation(s). As David Bridges writes, in these cases communities believe that in allowing members of the (former) subordinating group to cast their representations, they are reinforcing both the fact and perception of their subordination "as well as exposing themselves to potential misrepresentation."8

The final insider-outsider tension germane to this article pertains to the distinction between the academic researcher and the "non-academic" community being researched. This distinction is multifarious, reflecting not only contesting notions of research "legitimacy" and the motives for conducting research, but also the history of contact between any particular university and community, as well as sometimes dramatic differences between university and community cultures.

The question of legitimacy and "purity" with regard to research origins and processes can serve as a point of disconnection and distance between university researchers and those being researched. As Yolanda Suarez-Balcazar, Gary Harper, and Rhonda Lewis point out, the "entrenched conservatism" of discipline-defined research narrows the parameters within which research agendas and processes are deemed to be worthy of academic pursuit. Here it is from within the academic discipline, rather than the community, that research questions are articulated and research agendas are formalized. ${ }^{9}$ The motivation behind such 
"pure" academic-based research is first and foremost to add to the knowledge in the field and to publish in peer-reviewed scholarly journals, rather than to be of direct "use" to the community being researched. Indeed, as Philip Nyden points out, having one's research referred to as "applied" or "local" may be a subtle put-own rather than a complient within some academic circles. ${ }^{10}$

Not surprisingly the above research motivations may be regarded by the community under investigation as quite antithetical to their own more immediate concerns and problems. Further, as Minkler indicates, university researchers guided too rigidly by such motivations are apt to give ill attention to prior consultation with the communities they are working in or to be insufficiently concerned with related relationship building. Within the community being researched this can over time lead to a sense of being "overused" by academic institutions and a hardening of feelings toward outsider researchers.

Intrinsically related to the above tensions are very real and tangible differences between academic and non-academic community cultures. Two important issues here concern language and time. Language use is key to working with communities, and academics insensitive to the language norms in circulation within the communities in which they are working may convey a sense of condescension or paternalism through their use of discipline-specific jargon, whether intended or not. Regarding time, academic and non-academic communities may have very different senses of time as well as timetables. Here the communities under question may not be living their lives in accordance with semesters or terms. Conversely, university researchers may not be under the same types of time pressures that impact communities, particularly where the operations of community-based organizations are concerned. ${ }^{11}$

The above points constitute some of the major areas of insider-outsider tensions. Yet important questions exist regarding the basis of many of these tensions, and their endurance as potentially insurmountable problems. In the next section of the paper I re-examine these areas in light of their weaknesses, and I examine the complexity of insider-outsider distinctions in diasporic contexts.

\section{Complicating Insider-Outsider Distinctions}

The most violent and egregious representation of the researcher-researched distinction, namely criminal misconduct or abuse on the part of the researcher, has been thankfully addressed through greater adherence to international human rights law generally and through the creation of research oversight bodies in particular. Regarding the latter, such entities as the institutional review board (US and international) and such policies as the Tri-Council Policy Statement (Canada) work to ensure that research conducted on human subjects adheres to strict ethical standards. These mechanisms not only protect the "researched" from overt physical and mental abuse, but also mandate procedures regarding consent and disclosure, and participant knowledge of research goals and processes. ${ }^{12}$

A separate basic problem regarding the insider-outsider polemic concerns the notion of "groups." As noted, a fundamental manner in which insiders have been differentiated from outsiders rests on the notion of group membership, wherein anyone "outside" the group in question is deemed to be an "outsider" and anyone "inside" an "insider." Yet such a manner of distinguishing insiders from outsiders necessarily rests on assumptions of homogeneity within insider communities. Here insiders must be "the same" to a degree that sufficiently differentiates them from outsiders. Yet even a cursory glance at the illustrations noted earlier concerning groups immediately calls into question this manner of distinguishing insiders from outsiders. For example, the "gay community" is in fact a highly heterogeneous group, wherein such differentiating factors as race, ethnicity, class, and religion may in fact outweigh the shared characteristic of homosexuality in terms of a uniform group identity. This problem necessitates the creation of finer and finer identity descriptors (e.g. gay, white, Christian, working class) to uphold the status of "insider." As David Bridges notes, the problem here is that as we add more descriptors to define the identity of any given community "we are more likely to create people who stand in relation to it in some respects as an insider and in some respects as an outsider." ${ }^{13}$ Hence researchers are most often likely to be "partly" insiders based on their affinities with the community in question, and "partly" outsiders based on their differences, thereby disrupting the original distinction.

Notwithstanding the above complication, Bridges writes that on the particular note of researcher status, the insider researcher will always be something of an outsider in his or her community "by virtue of becoming a researcher." 14 This is particularly the case in communities that are culturally remote from universities and academe. Within communities that are not only culturally remote from but also have had historical animosity with universities, insider researchers may be seen as having "sold out" to the establishment and viewed with suspicion and distrust, despite their shared identification(s). ${ }^{15}$

\section{Insider-Outsider Distinctions in Diasporic Contexts}

The particular case of conducting research with diasporic communities, which will be the subject for the remainder of this article, adds complexity to the insider-outsider compli- 
cations addressed above. For one, certainly diasporic "communities," just as other general groupings, are in themselves highly heterogeneous. Factors discussed above such as class and levels of religiosity will also define sub-communities within diasporic contexts. Other factors such as personal migration history (e.g. exact reasons for leaving one's home country and exact reasons for coming to the host country) as well as generational standing (first, second, third, and so on) are more particular to newcomer settlements, and again add a great deal of nuance to how "insiders" and "outsiders" might possibly be distinguished. Further, transnationality as a defining feature of many diasporic communities introduces yet another set of complications regarding the insideroutsider dualism. As R. Cheran writes, the traditional categories of "home" and "host" lands in the context of migration and diasporas are being disrupted by the multiple homes and multiple belongings attended to and exhibited by refugees. ${ }^{16}$ This plurality of locations and homes erodes conceptualizations of the insider as one with a singular homeland and homeland attachment, and conversely of the outsider as one possessing multiple homelands and multiple belongings.

Yet despite the fact that there do exist complications regarding how insiders and outsiders might be differentiated, particularly within the very fluid contexts of diasporic communities, there exists a residual moral problem (or challenge) associated with the outsider in forced migration research, namely, to demonstrate the utility and "worthiness" of the research endeavour. It is to this issue that I now turn.

\section{Problems That Remain: Addressing the Dual Imperative}

As I note in the introduction to this piece, Karen Jacobsen and Loren Landau write of a "dual imperative" in forced migration research. The imperative is rooted in what the authors perceive to be two principal aims in refugee research, namely to satisfy rigorous academic standards while also ensuring that the knowledge and understanding generated by the research be used toward the advancement of refugee protection and the betterment of refugee policy. While the first imperative may be seen as a response to establishing research "legitimacy" and hence justifying its place in academe and satisfying the demands of academic peers, the second may be seen as stemming from a type of moral principal asserting that research into others' suffering can only be justified if alleviating that suffering is an explicit objective. ${ }^{17}$ To demonstrate the presence and functioning of the dual imperative in the research literature, Jacobsen and Landau write that most forced-migration research seeks to address and explain refugee issues "with the intention of influencing agencies and governments to develop more effective responses," and that that in comparison to non-humanitarian fields "there are relatively few studies that do not conclude with policy recommendations for NGOs, the UN or national governments." 18

The dual imperative described by Jacobsen and Landau has an intrinsic connection to the problem of the outsider researcher. As I indicate above, this concerns fulfilling the "second" component of the imperative, namely, to demonstrate the utility and "worthiness" of the research. I would like to advance here that to the degree that those engaging in forced migration research fulfill only the "first" component of the imperative (to meet high academic standards, to establish academic legitimacy) without sufficient attention to the "second" moral component, they necessarily create themselves as a kind of outsider. The kind of outsider I am referring to here is one who, owing to a lack of sufficient attention to the moral component, may convey unconcern for or disregard of the refugee community and its well-being. ${ }^{19}$ Now one certainly could argue that the act of making "policy recommendations" in itself contains a moral dimension in terms of motivation, dedication, etc. However the degree to which such recommendations actually add up to a moral act depends upon advocacy and follow through. Otherwise researchers here run the risk of merely (and passively) adhering to and reproducing a formative structure characteristic of scholarship in the field.

An "academic detachment" inattentive to above concerns reifies the researcher - researched distinction, and resurrects many of the ghosts associated with it, such as exploitation of knowledge and community "use." It is a much more stubborn and inflexible basis for distinguishing / creating the outsider than such things as group membership, conceptions of home, or generational standing. To transcend this particular kind of entrapment entails, as indicated, more strongly embracing a moral component, and this in turn entails entertaining types of research processes that undermine academic-community divisions.

\section{A Community-Based Participatory Approach}

Community-based participatory research (CBPR) is a quite radical orientation to conducting research when looked at through the lens of a traditional academic approach. Tracing its roots to the action research school developed by social psychologist Kurt Lewin in the 1940s and revolutionary alternative approaches to research that emerged from work with oppressed communities in South America, Asia, and Africa in the 1970s, CBPR is a collaborative endeavour that strives toward equitable involvement in the research process between the researcher and the community "researched." 20 There exists a range of definitions and conceptualizations of 
CBPR, extending from broad and generally "open" senses of the practice toward those that are more narrowly and contextually construed. The most encompassing definitions of CBPR position it as research rooted in the community, serving a community's interest, encouraging community participation at all levels, and geared toward affecting social change. $^{21}$

Principles of CBPR practice generally flow from the above conceptualization. For example, in writing about CBPR in the area of public health research, Barbara Israel and colleagues articulate nine essential principles of practice. These state that CBPR (1) recognizes community as a unit of identity, (2) builds on strengths and resources within the community, (3) facilitates collaborative, equitable partnerships in all phases of the research, (4) promotes co-learning and capacity-building among all partners, (5) integrates and achieves a balance between research and action for the mutual benefit of all partners, (6) emphasizes local relevance of public health problems and ecological perspectives that recognize and attend to the multiple determinants of health and disease, (7) involves systems development through a cyclical and iterative process, (8) disseminates findings and knowledge gained to all partners and involves all partners in the dissemination process, and (9) involves a long-term process and commitment. ${ }^{22}$

The fundamental characteristics of CBPR most germane to this study are firstly that the research "problem," or perhaps more appropriately, "need," is articulated with the community as opposed to on the community. This necessitates considerable investment in partnership building (principle number 3 above) and establishment of trust. However, the payoff is well worth the effort, as the researcher is far less likely to be viewed as a "problematizer," aloof from voices expressed by those directly experiencing the phenomenon. Secondly, research is conducted utilizing community strengths and resources (principle number 2 above). This means that community members are directly involved in the research process. Here universities and communities recognize that they each have unique resources to contribute. While, subject to their own training, community members may not be expected to carry out duties requiring a high degree of methodological skills, they nonetheless can carry out very essential roles, from community mobilizing and organizing to specified tasks in data processing and management. ${ }^{23}$ Finally, and perhaps most importantly here, the community has ownership of CBPR findings. Regarding this hallmark of the CBPR process, Minkler writes, "A fundamental tenet of CBPR involves its commitments to giving the study findings back to the community and facilitating strong community involvement in decision making about the use of those findings for action and social change." 24

The above points build a strong case for fulfilling the moral component of the dual imperative advanced by Jacobsen and Landau. They thereby weaken, at least in principle and theory, conditions within which a researcher may create him or herself as an outsider, particularly where the utility and worthiness of the research is in question. There is debate within academia about the degree to which CBPR fulfills the first component of the dual imperative (fulfillment of rigorous academic research standards and expectations). However, scholars such as Nyden and others are forcefully demonstrating the worthiness and utility of embracing CBPR approaches within academe. ${ }^{25}$

Conducting CBPR within diasporic communities is not without its complications.

In their critique of methodologies common in forced migration research, Jacobsen and Landau point out problems associated with becoming "too" involved with refugee communities, as well as difficulties associated with using local researchers (or, in the context of this article, "insiders"). While the authors are writing primarily about fieldwork in humanitarian situations such as refugee camps or other types of near diasporas, many of the situations they describe might very well also apply to conditions within far diasporas.

Regarding level of involvement with refugee communities, Jacobsen and Landau note that researchers living or working among refugees may be more susceptible to accepting "imagined" histories or becoming incorporated into refugees' survival strategies. This, the authors assert, may amount to a problem known as "reactivity," where "the active presence of the researcher potentially influences the behaviour and responses of the informants, thereby compromising the research findings." 26 However, while CBPR certainly entails a greater degree of community "involvement" on the part of the researcher(s), it does not mean that distinct roles and responsibilities in the research partnership are not maintained. Those engaging in CBPR in fact serve communities better by maintaining particular boundaries, the breach of which might seriously compromise research ethics.

With regard to difficulties associated with using local researchers, Jacobsen and Landau note two major issues. Firstly, there is the risk of bias, particularly where local researchers are employed to help with translation and other services involving data interpretation. Secondly, there is the risk of problems attached to subgroup affiliation on the part of local researchers, wherein particular loyalties may influence or affect the use of data (for example, as against other subgroups). As with the point concerning level of involve- 
ment with the community, both of these areas speak to the importance of maintaining rigour in the research process. For example, materials translated from English into the native language(s) of the community in question should be back-translated into English by native speakers without previous or direct involvement with the project (a strategy that Jacobsen and Landau advocate). ${ }^{27}$ In the case of the problems associated with subgroup loyalty, the research project must take measures to appropriately screen as well as train community members with this potential problem in mind.

Yet the larger and perhaps more fundamental issue that the above problems speak to concern the level of community "buy-in" to and involvement in the research mission and outcomes, and this is where CBPR may be particularly effective. To the degree that community members are a part of and have ownership in the research process and outcomes, they have more to lose personally if they do not adhere to standards of practice. Further, having a cross-section of community members involved in the actual generation of research "findings" creates a built-in mechanism for weeding out problems of bias as well as misuse of power associated with researcher status. ${ }^{28}$ As Nyden asserts, validity measures in community-based research actually increase and analytical red-herrings are avoided as multiple perspectives watch over the work. ${ }^{29}$

In all, engagement in CBPR allows the outsider academic researcher to be "less an outsider" and more a partner with the community concerned. As demonstrated above, this is accomplished first and foremost through the very aims of the research, which are to have an impact, and not merely the recommendation of an impact. As well, CBPR breaks down one of the most rigid factors separating communities from researchers, namely the perception and fear that the community will be (once again) "used" for research purposes, without receiving any real or tangible benefit. Further, CBPR disrupts the (potentially) myopic perspectives to which discipline-defined researchers are acutely vulnerable. Community needs, as Nyden writes, do not present themselves as departmental-specific problems (i.e.; a sociological problem, an economic problem). Rather they are by their nature interdisciplinary and holistic. ${ }^{30}$ This forces researchers to step out of their boxes and to entertain multiple angles on the issue at hand. Finally, CBPR is a sharing rather than an assertion of power, and for diasporic communities, this is certainly a welcoming note.

\section{Conclusion}

The designation of outsider researcher is perhaps ultimately unavoidable. There may always exist criteria, however minute, that distinguish an "us" from "them," and certainly diasporic communities are not immune to this. Yet some of the most fundamental ways in which outsiders are depicted and their statuses reified can be challenged and even undone. Of all areas of social and cultural research, refugee research is perhaps one of the most important contexts for doing so. Refugees, by virtue of their migration experiences and their frequently diminished levels of power within host societies, constitute a population particularly vulnerable to the exploits of academic researchers. Here overcoming obstacles presented by the insider-outsider distinction is not merely a methodological and academic concern, it is also one with an important moral dimension.

Jacobsen and Landau's articulation of the dual imperative in refugee research, namely satisfying rigorous academic research standards while also ensuring that the knowledge gained be used toward the advancement of refugee protection and policy, provides a very useful framework for critiquing the role of the academic researcher within diasporic contexts. The imperative is extended in this article towards providing insight about the degree to which researchers may perpetuate an outsider status, particularly where the moral component is lacking or only partially fulfilled. I have argued in this piece that community-based participatory research is one very effective means of addressing obstacles standing in the way of closing the insideroutsider gap, particularly in relation to research purposes and outcomes.

The "democratization of knowledge" is an inherent component of CBPR. Here institutions share their access to and their creation of knowledge, and research is far less exclusively the domain of universities alone. ${ }^{31}$ There may be no more pressing need for the democratization of knowledge than with and within diasporic communities, where knowledge turned into action defines a route toward better livelihood, and where researcher identities reshape towards more generative forms.

\section{Notes}

1. The particular diasporic communities I am referring to in the paper concern the "wider diaspora," or countries of asylum further afield. This may be contrasted with a "near diaspora," which pertains to neighbouring countries, or countries of first asylum. See Nick Van Hear, "Refugees in Diaspora: From Durable Solutions to Transnational Relations," Refuge 23, no. 1 (2006): 11.

2. R. Cheran, "Multiple Homes and Parallel Civil Societies: Refugee Diasporas and Transnationalism," Refuge 23, no. 1 (2006): 5.

3. Karen Jacobsen and Loren Landau, "The Dual Imperative in Refugee Research: Some Methodological and Ethical Considerations in Social Science Research on Forced Migration," Disasters 27, no. 3 (2003): 185-206. 
4. David Bridges, “The Ethics of Outsider Research," Journal of Philosophy of Education 35, no. 3 (2001): 371.

5. See Naomi Baumslag, Murderous Medicine: Nazi Doctors, $\mathrm{Hu}$ man Experimentation, and Typhus (New York: Praeger, 2005); Peter Williams, Unit 731: Japan's Secret Biological Warfare in World War II (New York: Free Press, 1989); James H. Jones, Bad Blood: The Tuskegee Syphilis Experiment (New York: Free Press, 1993).

6. Famous examples include the Stanford Prison Experiment (1971) as well as the Milgram Experiment (1963). See "Quiet Rage: The Stanford Prison Study,” videocassette, prod. Philip Zimbardo and Ken Musen, Psychology Department, Stanford University, 1991; Arthur Miller, The Obedience Experiments: A Case Study of Controversy in Social Science (New York: Praeger, 1986).

7. Meredith Minkler, "Ethical Challenges for the 'Outside' Researcher in Community-Based Participatory Research," Health Education and Behavior 31, no. 6 (2004): 689.

8. Bridges, 380 .

9. Yolanda Suarez-Balcazar, Gary Harper, and Rhonda Lewis, "An Interactive and Contextual Model of CommunityUniversity Collaborations for Research and Action," Health Education and Behavior 32, no. 1 (2005): 94.

10. Philip Nyden, "Academic Incentives for Faculty Participation in Community-Based Participatory Research,", manuscript, Center for Urban Research and Learning, Loyola University, Chicago [2002]: 6.

11. Minkler, 689.

12. Institutional Review Board Services, Ethics Review, $<$ http://www.irbservices.com/> (accessed January 28, 2007); Tri-Council Policy Statement: Ethical Conduct for Research Involving Humans, Guiding Ethical Principles, <http://www. ncehr-cnerh.org/english/code_2/> (accessed January 28, 2007).

13. Bridges, 372 .

14. Ibid.

15. Suarez-Balcazar, Harper, and Lewis, 90.

16. Cheran, 4.

17. Jacobsen and Landau, 186

18. Ibid, 185

19. The embedded assumption here is that "insiders" are inherently concerned about their communities' well-being, and that their research activities are motivated by and dedicated to this concern.
20. Minkler, 686.

21. R. Slove, "Research by the People, for the People," Futures 2 (1997): 541-549; L. Green, M. Daniel, C. Frankish, C Herbert, W. Bowie, and M. O'Niel, "Background on Participatory Research," in Doing Community-Based Research: A Reader, ed. D. Murphey, M. Scammell, and R. Sclove (Amherst: Loka Institute, 1997).

22. Barbara Israel, Amy Schulz, Edith Parker, Adam Becker, A. Allen III, and Ricardo Guzman, "Critical Issues in Developing and Following Community Based Participatory Research Principles," in Community Based Participatory Research for Health, ed. Meredith Minkler and Nina Wallerstein (San Francisco: Jossey-Bass, 2003). Of course enacting CBPR is a very complex and often political process, and the authors are careful to note that the principles are written as ideal goals, formed with the recognition that their achievement depends upon the context and purpose of the research, and the participants involved in the process.

23. Suarez-Balcazar, Harper, and Lewis.

24. Minkler, 693.

25. Nyden.

26. Jacobsen and Landau, 192.

27. Ibid., 198.

28. In qualitative research, an example of effectively using a crosssection of community members in the generation of findings is inter-rater review of coding schemes and the application of codes to transcripts, etc. See Richard Boyatzis, Transforming Qualitative Information: Thematic Analysis and Code Development (Thousand Oaks: Sage).

29. Nyden, 12.

30. Ibid., 7 .

31. Ibid., 9 .

Bruce Collet, PhD, is assistant professor of educational foundations and inquiry in the School of Leadership and Policy Studies, College of Education and Human Development at Bowling Green State University, and a scholar with the Centre for Refugee Studies, York University, Toronto. His research interests include immigrant and refugee education, religiosity within diasporic contexts, critical multiculturalism, and community-based participatory research. 